\title{
Gustatory cross adaptation between salts
}

DONALD H. MCBURMEY AND JOHN A. LUCAS

UNIVERSITY OF TENNESSEE

Adaptation of the tongue to any of four different salts tested lowered the estimated magnitude of some other salts, contrary to previous reports. A separate mechanism is not required to code the taste of each salt.

No evidence has ever been found of cross adaptation between salty tasting substances either psychophysically or electrophysiologically. Hahn (1949) compared 24 different salts for cross adaptation in humans in an extensive psychophysical study and found that "the adaptation to any given concentration of salt is always limited in a truly astounding manner to the contained (adapting) salt" (p. 219). A similar phenomenon was found by Beidler (1962) where adaptation to $0.1 \mathrm{M} \mathrm{CaCl} 2$ did not influence the response of the rat chorda tympani to $0.1 \mathrm{M} \mathrm{NaCl}$, even though both substances are known to affect the same taste cells. These results are of wide importance in taste theory, because they mean that at least 24 different receptor sites or mechanisms are required for salt sensitivity alone; and amazing degree of specificity. This is even more surprising since cross adaptation can occur between stimuli of the different basic taste qualities (Dallenbach \& Dallenbach, 1943) particularly between sour and sweet.

In the course of another study, the chance observation was made that adaptation to $\mathrm{KCl}$ did in fact alter the taste of $\mathrm{NaCl}$ (McBurney, 1965). The present study was designed to further demonstrate the effect and test its generality.

\section{Prelimimary Study}

Since adaptation has its greatest effect on solutions which are close in intensity to the adapting solution (McBurney, in press), it was necessary in a preliminary study to choose concentrations of each salt which would give the same subjective magnitude. Ss judged the intensity of eight salts by the method of magnitude estimation with no modulus under HOH adaptation. From the intensity function for each salt a value was chosen to be equal to $0.1 \mathrm{M} \mathrm{NaC1}$. We found for our two anions $\left(\mathrm{Cl}^{-}\right.$and $\left.\mathrm{Br}^{-}\right)$that the anion made no contribution to intensity. For each cation the values found for the chloride and bromide seemed to be random samples from the same population. This is also true for electrical recording data (Beidler, 1953). For this reason we pooled the data of the anions and made a single estimate for each cation. These values are given in Table 1.

\section{Method}

Human Ss sat with the tongue extended between the lips so that a flow system delivered the solutions to the entire exposed dorsal tongue surface, eliminating the influence of saliva. All solutions were
Table 1

Solutions of Equal Subjective Intensity

$$
\begin{aligned}
& \mathrm{NaCl}, \mathrm{NaBr} \cdot \text {. } . . .0 .1 \mathrm{M} \\
& \mathrm{KC1}, \mathrm{KBr} \text {. . . . . . } 0.11 \mathrm{M} \\
& \mathrm{NH}_{4} \mathrm{C} 1, \mathrm{NH}_{4} \mathrm{Br} \cdot \cdot \cdot \cdot 0.051 \mathrm{M} \\
& \mathrm{CaCl}_{2}, \mathrm{CaBr}_{2} \text {. . . . } 0.026 \mathrm{M}
\end{aligned}
$$

maintained at $34^{\circ} \mathrm{C}$ in a water bath and were delivered through the same tube.

All solutions were made in distilled HOH. Each of four groups of Ss judged all eight stimuli (plus eight weaker and 16 stronger stimuli to avoid having all of the stimuli of the same intensity) once under adaptation to one of the chlorides and also after $\mathrm{HOH}$. Adaptation order was counterbalanced and order of stimuli was random and different for each $\mathrm{S}$.

\section{Results}

The geometric means of the magnitude estimates were computed for the eight matched solutions. The data are shown in Fig. 1. The circles give the subjective magnitude after $\mathrm{HOH}$ adaptation and the triangles after $\mathrm{NaCl}$ adaptation. The line connecting the points shows the amount of change. The horizontal lines indicate \pm 1 standard error of the mean difference (matched samples).

\section{Discussion}

In each group the adapting solution is also used as a test stimulus. The change in this stimulus (e.g. NaC1 in Fig. 1) represents ordinary adaptation not cross adaptation. Since the taste of salts adapts completely these changes may be taken as a standard in judging the completeness of adaptation. It is apparent that in most cases the effect is quite small (only 15 out of 28 of the individual cross-adaptation effects are significant at the .05 level). However, of 28 pairs, 26 are positive and none negative (not counting the four cases of ordinary adaptation). It appears that we have strong evidence for a weak effect.

In each group, however, the bromide which has the same cation as the adapting solution (e.g. $\mathrm{NaBr}$ in the NaC1 group) adapted completely. In fact the bromides on the whole behave as do the comparable chlorides. Whether this would be true for other anions, we cannot say.

We see no satisfactory way of accounting for Hahn's failure to obtain cross adaptation. Although most of his adapting solutions were weaker than ours, he did use some as strong as $3 \mathrm{M}$. The most likely reason for the absence of cross adaptation in his study is the use 

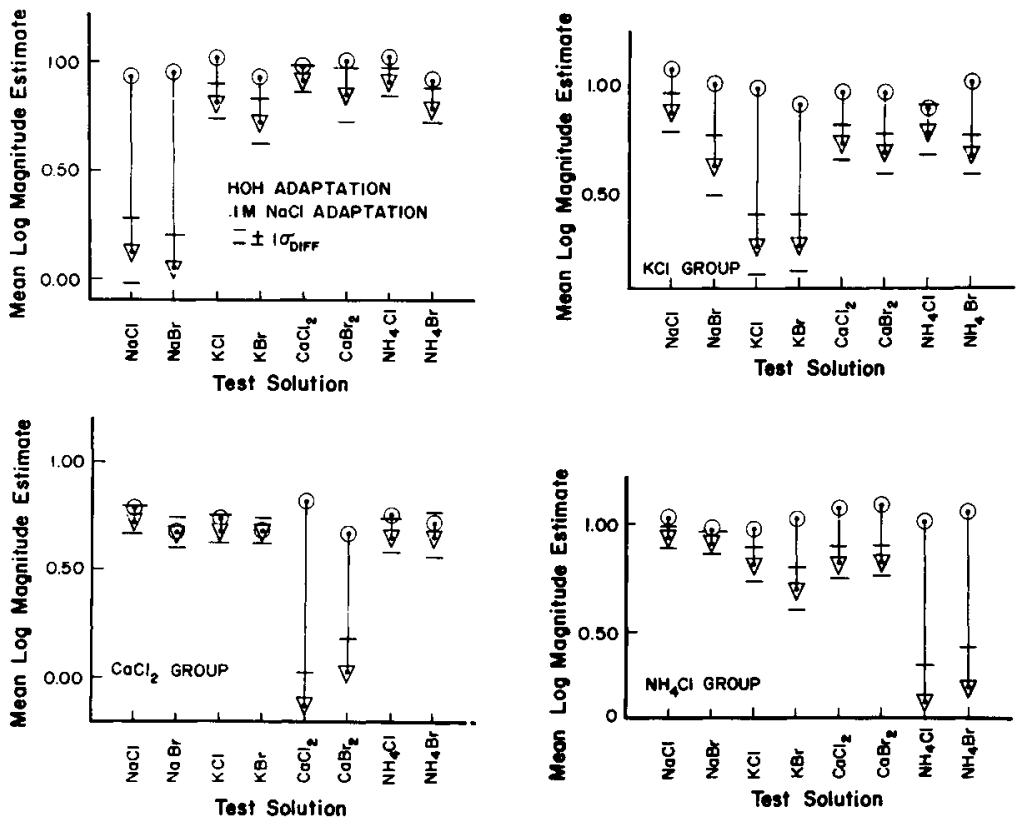

Fig. 1. Estimated magnitude of salt solutions after HOH or salt adaptation.

of thresholds to measure sensory effect. It is conceivable that the detection threshold is not changed by cross adaptation, but only the intensity of suprathreshold solutions. However there are several puzzling aspects of his results. His NaC1 thresholds were extremely low; $7 \times 10^{-7} \mathrm{M}$ after $\mathrm{HOH}$ adaptation compared to a median $\mathrm{HOH}$ adapted threshold $1.4 \times 10^{-4}$ found by McBurney \& Pfaffmann (1963). Also, his $0.01 \mathrm{M}$ adapted threshold of $3.6 \times 10^{-4} \mathrm{M}$ is below the adapting concentration. According to Bartoshuk, McBurney, \& Pfaffmann (1964) this would be in the sour-bitter subadapting range so that the quality of salty could not have been perceptible. Evidently Hahn is restricting his definition of salts here to include only those salts that have the typical salty taste. For example, $\mathrm{BeCl}_{2}$ which is sweet cross-adapted with $\mathrm{BeBr}_{2}$ and $\mathrm{BeSO}_{4}$. Also, among salts with a bitter taste, $\mathrm{MgCl}_{2}$ affected $\mathrm{NH}_{4} \mathrm{I}$ and $\mathrm{CuCl}_{2}$, for example. It would seem unlikely that sweet and bitter qualities would show cross adaptation and not salty within such a chemically well defined group as salts.

There is not necessarily any discrepancy between these results and those of Beidler. It is obvious that physiological evidence could be found if we knew the correct parameter to attend to. Also, in our experiment $\mathrm{CaCl}_{2}$, which he used as the adapting solution, give very weak cross adaptation.

We hoped that there would be enough differences in amount of cross adaptation between different stimuli to be able to get an idea of the number of sites or mechanisms responsible for salt taste coding from the way in which the pairs grouped themselves, but the effect is too small and similar in most cases. It appears now that the overall intensity of taste may not be the ap- propriate dependent variable. Further pilot results indicate that the salty taste of each salt is affected more than the overall intensity. Measuring the changes in saltiness should give us a more sensitive and useful measure of cross adaptation. We can state confidently, however, that the number of sites responsible for the coding of the salt taste is less than the number of salts.

Cross adaptation has been used fruitfully in the study of coding mechanisms in other senses. Now that the phenomenon has been demonstrated for salts, we feel that cross adaptation may be of considerable use in the study of gustatory coding.

\section{References}

Bartoshuk, Linda M., McBumey, D. H., \& Pfaffmann, C. Taste of sodium chloride solutions after adaptation to sodium chloride: Implications for the "water taste." Science, 1964, 143, 967-968.

Beidler, L. M. Properties of chemoreceptors of the tongue of rat. J. Neurophysiol., 1953, 16, 595-607.

Beidler, L. M. Taste receptor stimulation. In J. A. V. Butler, H. E. Huxley, \& R. E. Zirkle (Eds.), Progress in biophysics and biophysical chemistry. Oxford: Pergamon Press, 1962. Vol. 12, Pp. 107-151.

Dallenbach, J. W., \& Dallenbach, K. M. The effects of bitter adaptation on sensitivity to the other taste qualities. Amer. $J$. Psychol., 1943, 56, 21-31.

Hahn, H. Beiträge zur Reizphysiologie. Heidelberg: Scherer, 1949. McBumey, D. H. A psychophysical study of gustatory adaptation. (Doctoral dissertation, Brown University), Ann Arbor, Michigan: University Microfilms, 1965, No.65-2223.

McBurney, D. H. Magnitude estimation of the taste of sodium chloride after adaptation to sodium chloride. J. exp. Psychol., in press.

McBurney, D. H., \& Pfaffmann, C. Gustatory adaptation to saliva and sodium chloride. J. exp. Psychol., 1963, 65, 523-529. 